\title{
Inhibition of the Oxidation of Carbon Fibres and Composites
}

\author{
Pierre Ehrburger* and Eric Dallies-Labourdette
}

(Received November 18, 1991)

\begin{abstract}
Centre de Recherches sur la Physico-Chimie des Surface Solides, 68200 Mulhouse, France *to whom all correspondance should be sent
\end{abstract}

\begin{abstract}
The effect of a thin silica coating on the oxidation of carbon fibres has been investigated in the temperature range $600-1200^{\circ} \mathrm{C}$. Silica was deposited by thermal cracking of an organic precursor (tetraethoxysilane). The protection of carbon fibre by the coating consists first in an almost complete, but limited in time, resistance to oxidation. Thereafter, oxidation of the carbon becomes noticeable, but at a smaller rate than for the uncoated fibre. The change in efficiency of the protection during oxidation are discussed in terms of modification of surface properties of the carbon, total surface area and active surface area, and of thermomechanical characteristics of the carbon-coating interface.
\end{abstract}

KEYWORDS: Carbon fibre, Oxidation inhibition, Silica coating, Active sites

\section{Introduction}

Carbon fibres and carbon/carbon (C/C) composites have outstanding mechanical properties but they are very sensitive to oxidation which limits their use for applications at temperature above $500^{\circ} \mathrm{C}$. As an example, the lifetime in air of $\mathrm{C} / \mathrm{C}$ composite under static load decreases from $400 \mathrm{hrs}$ at $360^{\circ} \mathrm{C}$ to nearly zero at $500^{\circ} \mathrm{C}^{1}$. Therefore, extensive work has been carriedout in order to protect carbon materials from oxidation ${ }^{2)-3)}$. There are basically two ways to decrease the oxidation rate of carbon: i) inhibition by the presence of poisoning agents like boron or phosphorus compounds and ii), formation of a protective coating. The concepts involved in both approaches have been recently discussed along with their advantages and their limitations in designing a protection of carbon against oxidation $^{4}$. At moderate temperature, the lowering of the oxidation rate may be achieved by inhibition technique, i.e. blockage of the active surface sites responsible for carbon gasification. Magne et al. ${ }^{5)}$ found that small amounts of metaphosphoric acid, $\mathrm{HPO}_{3}$, can lower the oxidation rate of graphite by a factor 20. In a similar way $\mathrm{POCl}_{3}$ inhibits the oxidation of graphite and a strong interaction of the additive with the edge carbon atoms has been postulated ${ }^{2}$. At higher temperatures the efficiency of the inhibitors vanishes due to their volatility. As a result, efficient protection can only be obtained by oxidation resistant coatings which will act as diffusion barriers or getters for oxygen $^{3}$. The present study deals with the physicochemical aspects of the protection by a thin silica coating of carbons fibres against oxidation in dry air at temperatures below $1000^{\circ} \mathrm{C}$. Under these conditions both effects, true inhibition due to active site blockage and diffusion barrier may occur. The effect of the silica coating on the carbon reactivity will be examined from the point of view of the overall decrease in oxidation rate and of the modification of the surface properties of the carbon substrate. The changes in the silica-carbon interface will be followed during oxidation and related to the protective effect of the coating.

\section{Experimental Procedures}

\subsection{Deposition of Silica on Carbon Fibres}

Carbon surfaces can be coated with a continuous 


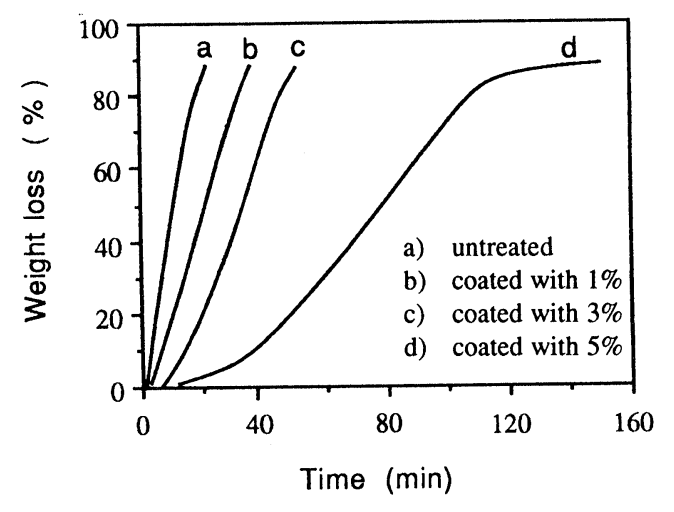

Fig. 1 Weight loss of carbon fibre during oxidation in air at $900^{\circ} \mathrm{C}$ : (a) untreated, (b) coated with $1 \%$ silica, (c) coated with $3 \%$ silica, (d) coated with $5 \%$ silica.

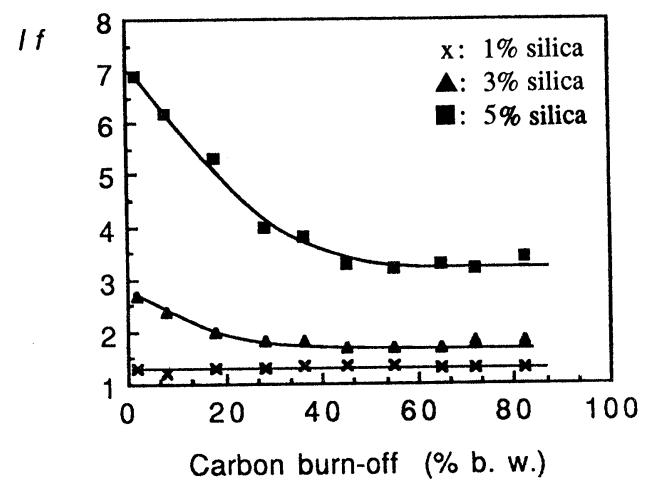

Fig. 2 Inhibition factor (If) of coated fibre as a function of burn-off at $900^{\circ} \mathrm{C}$ : (x) $1 \%$ silica, (A) $3 \%$ silica, (ם) $5 \%$ silica.

silica film by chemical vapour deposition of tetraethoxysilane (TEOS $)^{6-7)}$. The deposition process starts by cracking of TEOS on the carbon active sites and thereafter the whole surface can be covered by silica ${ }^{7}$. Using the same procedure polyacrylonitrilebased carbon fibres have been covered with silica at $600^{\circ} \mathrm{C}$ in vacuum before characterization and oxidation. Carbon fibres with amounts of deposited silica ranging from 1 to $5 \%$ by weight have been prepared batchwise (2 grams each) by this procedure.

\subsection{Oxidation Treatment and Surface Area Determinations}

Uncoated and silica-coated carbon fibres are oxidized in a stream of dry air at a flow rate equal to
$61 / \mathrm{hr}$. Isothermal oxidations have been performed in the temperature range $650-1200^{\circ} \mathrm{C}$ using a gravimetric system. The change of the carbon-silica interface during oxidation at $900^{\circ} \mathrm{C}$ has been followed by measuring total surface area (TSA) and active surface area (ASA) for uncoated and silica-coated samples. TSA has been determined by krypton adsorption at $-196^{\circ} \mathrm{C}$ using the BET equation. ASA has been measured by oxygen chemisorption at $300^{\circ} \mathrm{C}$ for $15 \mathrm{hrs}$ with an oxygen pressure equal to $70 \mathrm{~Pa}$ according to a procedure described elsewhere ${ }^{8}$. The amount of $\mathrm{CO}$ and $\mathrm{CO}_{2}$ released during thermal desorption up to $950^{\circ} \mathrm{C}$ have been determined by mass spectrometry at a heating rate of $5 \mathrm{~K} / \mathrm{min}$ followed by a treatment time of $30 \mathrm{~min}$ at the final temperature. The area occupied by an active site was taken as equal to $0.083 \mathrm{~nm}^{2}$ 9).

\section{Results and Discussion}

\subsection{Oxidation of carbon fibres}

The weight loss of carbon as a function of time during oxidation at $900^{\circ} \mathrm{C}$ is shown in Fig. 1 for different amounts of deposited silica. A protective effect is found for amounts of deposited silica equal to 3 and $5 \%$, respectively. It is also seen that the time elapsed before oxidation starts (induction period), increases with increasing amount of silica coating. The efficiency of the protective effect can be determined by a so-called inhibition factor, If, which is the ratio of the oxidation rate of the unprotected fibre to the rate for the silicacoated fibre. The change of the inhibition factor with carbon burn-off at $900^{\circ} \mathrm{C}$ is shown for different silica amounts in Fig. 2. If decreases significantly during oxidation and remains nearly constant only after $40 \%$ burn-off. The same trend is found at different temperatures of oxidation, the protective effect decreasing with increasing temperature particularly at low levels of burn-off (Fig. 3).

\subsection{Change in the carbon-silica interface during oxidation}

Oxidation of the carbon induces morphological changes as seen by scanning electron microscopy (SEM). Before oxidation a thin and flawless silica film can hardly be distinguished from the carbon substrate (Fig. 4). Once the carbon has been completely oxidized, a silica tube remains with the characteristic surface topography of the ex-acrylic fibre (Fig. 5). The access 


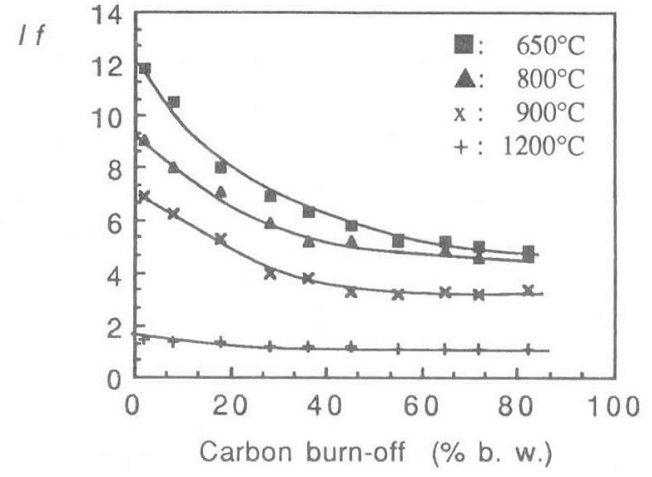

Fig. 3 Inhibition factor (If) of fibre coated with 5\% silica as a function of burn-off at different temperatures: (四) $650^{\circ} \mathrm{C}$, (4) $800^{\circ} \mathrm{C},(\mathrm{x}$ ) $900^{\circ} \mathrm{C}$, (+) $1200^{\circ} \mathrm{C}$.

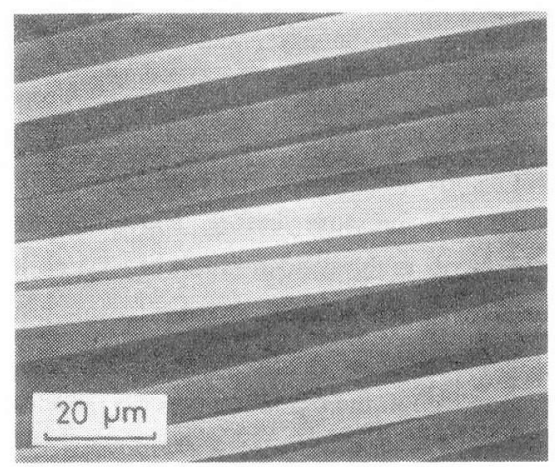

Fig. 4 SEM micrograph of silica-coated carbon fibres.

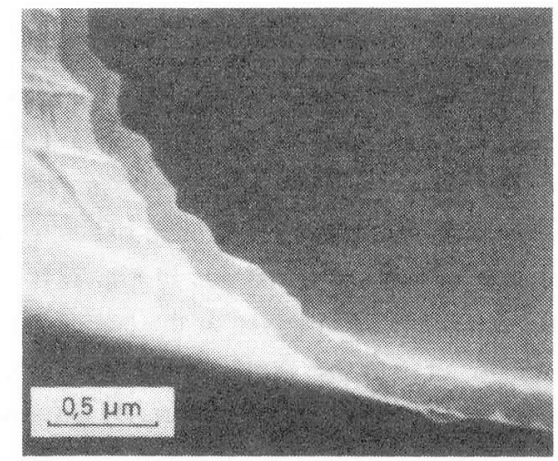

Fig. 5 SEM micrograph of edge of silica tube after oxidation of the carbon fibre.

of oxygen to the coated carbon fibre can be estimated by the determination of ASA which is not sensitive to
Table 1 ASA of untreated and silica-coated carbon fibers

\begin{tabular}{ll}
\hline \multicolumn{1}{c}{ Fibre } & $\begin{array}{l}\text { A S A } \\
\left(\mathrm{m}^{2} / \mathrm{g}\right)\end{array}$ \\
& \\
\hline Untreated & 0.06 \\
Coated with 1\% silica & 0.03 \\
Coated with 3\% silica & 0.01 \\
Coated with 5\% silica & 0.01 \\
\hline
\end{tabular}

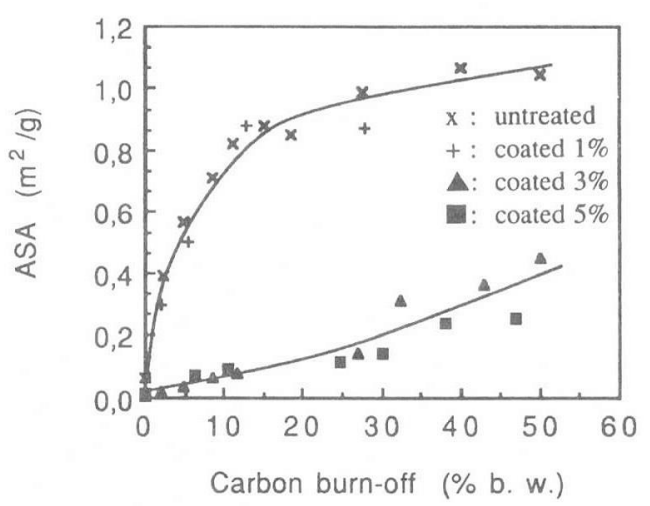

Fig. 6 Change in ASA as a function of burn-off of carbon fibre at $900^{\circ} \mathrm{C}$ : (x) untreated, (+) coated with $1 \%$ silica, $(\mathbf{\Delta})$ coated with $3 \%$ silica, coated with $5 \%$ silica.

silica. ASA values prior to and after silica deposition are listed in Table 1. As expected ASA decreases after silica deposition, indicating that a partial blockage of the carbon active sites is attained. The change in ASA during oxidation at $900^{\circ} \mathrm{C}$ of untreated and silica-coated samples is shown in Fig. 6. There is no significant difference between the untreated fibre and the sample with $1 \%$ silica. For higher amounts of deposited silica, ASA is less developed than for the untreated fibre which indicate that a partial blockage of the active sites remains even after oxidation. The change of the carbonsilica interface during oxidation at $900^{\circ} \mathrm{C}$ has been followed by measuring TSA and ASA of a sample coated with $4 \%$ silica. The same sample has been submitted to increasing levels of burn-off and the results are shown in Table 2. It is seen that TSA values for the coated fibre are somewhat smaller than for the noncoated one until 30\% burn-off. Thereafter a higher TSA 
Table 2 TSA and ASA of untreated and silica-coated fibers at different levels of burn-off

\begin{tabular}{lcccc}
\hline \multirow{2}{*}{ Sample } & Burn-off & \multicolumn{1}{c}{ TSA } & ASA & ASA/TSA \\
\cline { 3 - 4 } & $(\%)$ & \multicolumn{2}{c}{$\left(\mathrm{m}^{2} / \mathrm{g}\right)$} & \\
\hline & 0 & 0.6 & 0.06 & 0.10 \\
& 10 & 1.5 & 0.8 & 0.54 \\
Uncoated fibre & 20 & 1.7 & 0.9 & 0.50 \\
& 30 & 2.5 & 1.0 & 0.40 \\
& 50 & 2.2 & 1.0 & 0.46 \\
\hline & & & & \\
\hline \multirow{3}{*}{ Fibre coated with } & 0 & 0.4 & 0.03 & - \\
$4 \%$ silica & 4 & 0.6 & 0.06 & 0.10 \\
& 13 & 0.9 & 0.13 & 0.14 \\
& 30 & 1.6 & 0.24 & 0.15 \\
& 50 & 4.9 & 0.65 & 0.13 \\
\hline
\end{tabular}

is developed in presence of silica. The ratio ASA/TSA is much smaller for the silica-coated sample than for the untreated one. It must however be kept in mind that the carbon TSA may be somewhat smaller than the measured TSA value. Taking in account the specific surface area of the silica film measured after complete oxidation of the fibre $\left(13 \mathrm{~m}^{2} / \mathrm{g}\right)$ and assuming a complete decohesion between the silica deposit and the fibre, the ratio ASA/carbon TSA would be equal to 0.17 which is still much smaller than for the unprotected fibre. Hence it is concluded that the presence of a silica coating affects the ASA/TSA ratio of the carbon during oxidation.

\subsection{Protective effect of the silica coating}

The silica coating has two effects on the oxidation kinetics of carbon, an increase of the induction period and a decrease of the oxidation rate. The increase of the induction period may originate either from the time lag before steady state oxygen diffusion and/or from a lowering of the oxygen concentration at the carbon surface in steady state diffusion conditions. Assuming a density equal to that of fused silica $\left(2.2 \mathrm{~g} / \mathrm{cm}^{3}\right)$, the mean thickness of the coating corresponding to 1,3 and $5 \%$ of deposited silica is equal to 8,24 and $40 \mathrm{~nm}$ respectively. The diffusion coefficient of oxygen in vitreous silica at $900^{\circ} \mathrm{C}$ is equal to $2.6 \times 10^{-13} \mathrm{~m}^{2} / \mathrm{s}$ according to the work of Norton ${ }^{10)}$. The change in concentration of oxygen at a distance $x$ beneath the airsilica interface can be derived from the second equation of Fick. For a constant supply of oxygen from the gas phase, the concentration of oxygen, $c$, at a depth $\mathrm{x}$ from the interface is given as a function of time $\mathfrak{t}^{11}$.

$$
c(x, t)=c_{0} \operatorname{erfc}\left(\frac{x}{2 \sqrt{D t}}\right)
$$

where $\mathrm{D}$ is the diffusion coefficient of oxygen in silica, $c_{0}$ is the concentration of oxygen at $x=0$ (solubility of oxygen in silica) and erfc is the complementary error function. From this equation, the time elapsed to reach an oxygen concentration at the carbon silica-interface equal to $95 \%$ of the atmospheric oxygen concentration is about $1 \mathrm{~s}$. Since the induction period corresponds to nearly $10 \mathrm{~min}$, one may conclude that the diffusion of oxygen in unsteady conditions cannot explain the time lag observed when the coated fibre is exposed to air. A similar result can be found for oxidation at $650^{\circ} \mathrm{C}$. Thus, the induction period would originate from a diffusion barrier effect. The permeation rate of a gas across a layer can be expressed as:

$$
J=c_{0} D \frac{P_{0}-P_{i}}{x}
$$

where $J$ is the permeation rate per unit area, $P_{o}$ and $\mathrm{P}_{\mathrm{i}}$ is the gas pressure before and after the layer respectively, $\mathrm{c}_{0}$ is the concentration of oxygen in silica, $x$ is the layer thickness and D is the diffusion coefficient of oxygen. When diffusion through the silica film is the limiting step in the oxidation process then the partial pressure of oxygen at the silica-carbon interface, $P_{1}$, can be neglected. From the permeation results of Norton ${ }^{10)}$, the concentration of oxygen dissolved at $900^{\circ} \mathrm{C}$ in vitreous silica is equal to $7.6 \times 10^{-7} \mathrm{~mole} / \mathrm{m}^{3} \mathrm{~Pa}$ which corresponds to $1.5 \times 10^{-2} \mathrm{~mole} / \mathrm{m}^{3}$ of silica for $2 \times 10^{4}$ $\mathrm{Pa}$ oxygen pressure applied. Hence the permeation rate of oxygen through a silica layer of $40 \mathrm{~nm}$ in thickness at $900^{\circ} \mathrm{C}$ and for $2.0 \times 10^{4} \mathrm{~Pa}$ is equal to $1.5 \times 10^{-7}$ $\mathrm{mole} / \mathrm{m}^{2} \mathrm{~s}$. The carbon weight loss at $900^{\circ} \mathrm{C}$ corresponding to a permeation limited oxidation rate is compared to the experimental one in Fig. 7. It is seen that the oxidation lag observed at the beginning of the exposure to air may be explained by the permeation rate of oxygen through the silica layer. By extrapolating Norton's data to $650^{\circ} \mathrm{C}$, it can also be shown that the induction period observed at that temperature ( $\sim 50 \mathrm{~min})$ is due to the limiting permeation rate of oxygen through the silica film.

The increase of the oxidation rate after the induction period suggests that oxygen no longer diffuses through 


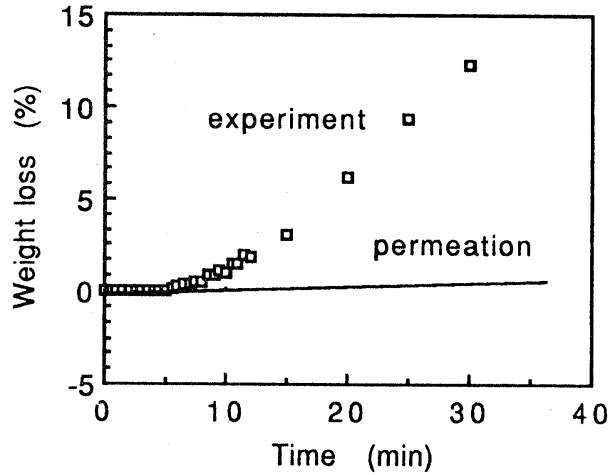

Fig. 7 Comparison of the calculated weight loss by permeation with the actual one at $900^{\circ} \mathrm{C}$.

a continuous silica film. In order to confirm this hypothesis, the supply of oxygen was stopped after $2 \%$ burn-off at $900^{\circ} \mathrm{C}$ and the weight loss ceased immediately. After 10 min oxygen was again admitted in the reaction chamber. No induction period was found in that case which indicates that the silica layer was irreversibly damaged. The enhanced carbon reactivity is certainly due to the diffusion of oxygen through fissures in the coating. The occurrence of microcracks is generally attributed to the mismatch of thermal expansion coefficient between the carbon substrate and the protective layer. In fact the thermal expansion coefficient for fused silica and for carbon fibre-perpendicular to the fibre axis-differs by one order of magnitude ( $\alpha=5.5 \times 10^{-7} \mathrm{~K}^{-1}$ or silica, $\alpha \mathrm{T} \sim 7 \times 10^{-6} \mathrm{~K}^{-1}$ for carbon fibre $^{12)}$. Furthermore the formation of volatile carbon oxides at the interface may also contribute to the formation of fissures in the silica coating. Since the deposited silica has a much smaller density than fused silica, it may however accommodate to some extent the propagation of microcracks through the layer. Whatever the precise thermomechanical behaviour of the deposited coating, it may be admitted that the lowering of the protective effect is essentially due to the formation of fissures. The ratio ASA/TSA is smaller in presence of the silica coating which points to a modification in the surface properties of the carbon fibre in the vicinity of a fissure. Furthermore if one considers that gas diffusion through microcracks is the limiting oxidation step, a modification of the gas composition at the carbon interface, principally an increase of the concentration of $\mathrm{CO}_{2}$ may be expected. In order to verify this

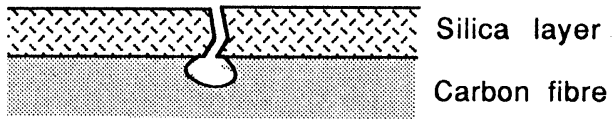

Fig. 8 Schematic of carbon oxidation after fissuration of the silica coating.

Table 3 Comparison of surface properties of carbon fibre oxidized at $900^{\circ} \mathrm{C}$ in air and carbon dioxide at $5 \%$ burn-off

\begin{tabular}{lccc}
\hline \multirow{2}{*}{ Fibre } & TSA & ASA & ASA/TSA \\
\cline { 2 - 3 } & \multicolumn{2}{c}{$\left(\mathrm{m}^{2} / \mathrm{g}\right)$} & \\
\hline Oxidized in air & 1.5 & 0.57 & 0.38 \\
Gasified in carbon dioxide & 12.0 & 0.62 & 0.05 \\
\hline
\end{tabular}

hypothesis unprotected carbon fibres have been submitted to a $5 \%$ burn-off at $900^{\circ} \mathrm{C}$ in $\mathrm{O}_{2}$ and $\mathrm{CO}_{2}$ respectively. The comparison of their surface properties indicates that the ratio ASA/TSA is much smaller in the case of a gasification in $\mathrm{CO}_{2}$ (Table 3). It is well known that carbon gasification in $\mathrm{CO}_{2}$ develops markedly the surface area and the microporosity. ASA, however, is not affected in the same way. Similar observations have already been reported for the gasification of cokes in $\mathrm{O}_{2}$ and $\mathrm{CO}_{2}$, the ratio ASA/TSA being also much smaller when coke is gasified in $\mathrm{CO}_{2}{ }^{13}$ ). These results substantiate a kind of 'activation effect' during the oxidation of the ${ }_{0}$ coated fibre which develops the carbon surface beneath the microcracks (Fig. 8). Once the oxidation of the coated fibre starts at fissures in the coating, the carbon-silica interface is irreversibly damaged and the protective effect of the layer is reduced.

\section{Conclusion}

Deposition of a thin silica coating on carbon fibres by chemical vapour deposition leads to two main effects on their behaviour against oxidation, a complete protection period with almost no carbon loss and a decrease of the oxidation rate afterwards. The duration of complete protection period depends on the temperature at which oxidation is carried-out and is mainly due to a limited permeation rate of oxygen through a tight silica coating. Microfissuration of the silica coating 
during oxidation induces a decrease in the protective effect. The modification of the silica-carbon interface during oxidation indicates that once the protective layer is fissured, the carbon develops of surface texture which is comparable to the one obtained in an activation process. Hence the efficiency of a protection largely depends on the thermomechanical properties of the carbon-coating interface.

\section{References}

1) E. Fitzer, Carbon 16, 3 (1977).

2) D.W. McKee, in "Chemistry and Physics of Carbon" Vol. 16, P.A. Thrower Ed., Dekker N.Y. (1981) p. 1.

3) J.S. Strife and J.E. Sheenan, Ceramic Bulletin 67, 369 (1988).

4) P. Ehrburger, in "Carbon Fibers, Filaments and Composites" J.L. Figueiredo et al. Eds, Kluwer Academic Pub. (1990) p. 327.

5) P. Magne, H. Amariglio and X. Duval, Bull. Soc.
Chim. France 6, 2005 (1971).

6) W.P. Hoffman and P. Ehrburger, Proc. 4th International Carbon Conference, Baden-Baden, 338 (1986).

7) W.P. Hoffman and P. Ehrburger, J. Analytical and Applied Pyrolysis 15, 275 (1989).

8) P. Ehrburger, F. Louys and J. Lahaye, Carbon 27, 389 (1989).

9) N.R. Laine, F.J. Vastola and P.L. Walker Jr., J. Phys. Chem. 67, 2030 (1963).

10) F.J. Norton, Nature 12, 701 (1961).

11) J. Zarzycki, in "Les Verres et l'Etat Vitreux", Masson Ed., Paris, (1982) p. 240.

12) W.N. Reynolds, in "Chemistry and Physics of Carbon" Vol. 11, P.L. Walker Jr. and P.A. Thrower Eds., Dekker N.Y. (1973), p. 2.

13) J. Lahaye, P. Soulard, G. Prado and P. Ehrburger, P. (1988) Proceedings of the Conference "Carbon ' 88 ", The University of Newcastle-Upon-Tyne, 322 (1988). 